Revue des patrimoines

27 | 2015

Le cheval et ses patrimoines (2e partie)

\title{
Les représentations du cheval dans l'œuvre d'un artiste à la fin du XIXe siècle : Armand Charnay
}

Danièle Miguet

\section{OpenEdition}

Journals

Édition électronique

URL : http://journals.openedition.org/insitu/12017

DOI : 10.4000/insitu. 12017

ISSN : 1630-7305

Éditeur

Ministère de la culture

Référence électronique

Danièle Miguet, "Les représentations du cheval dans l'œuvre d'un artiste à la fin du XIXe siècle : Armand Charnay », In Situ [En ligne], 27 | 2015, mis en ligne le 02 novembre 2015, consulté le 30 avril 2019. URL : http://journals.openedition.org/insitu/12017 ; DOI : 10.4000/insitu.12017

Ce document a été généré automatiquement le 30 avril 2019.

\section{(c) $($ i) $(9)$}

In Situ Revues des patrimoines est mis à disposition selon les termes de la licence Creative Commons Attribution - Pas d'Utilisation Commerciale - Pas de Modification 4.0 International. 


\title{
Les représentations du cheval dans l'œuvre d'un artiste à la fin du XIXe siècle: Armand Charnay
}

\author{
Danièle Miguet
}

\section{Armand Charnay}

Le nom d'Armand Charnay reste sans doute méconnu du grand public. Armand Charnay naît à Charlieu, dans la Loire en 1844 et meurt à Paris en 1915, après avoir passé une grande partie de sa vie à Marlotte, en forêt de Fontainebleau. Fils de notaire, sa vocation d'artiste est précoce; il s'exerce dès son plus jeune âge à crayonner des personnages et des animaux. Venu à bout des réticences paternelles, il s'installe à Paris en 1865 pour se perfectionner. De caractère indépendant, il ne suit que très peu de temps les cours de maîtres réputés comme Isidore Pils et Feyen-Perrin, préférant peindre sur le motif, dessiner et graver à l'eau-forte pour plusieurs journaux, notamment La Chasse Illustrée. Dès 1865, il est remarqué au Salon des artistes français; il n'a que 21 ans mais ses envois réguliers sont déjà des valeurs sûres. Il obtiendra d'ailleurs une médaille d'argent à l'Exposition universelle de 1889, à Paris. Son amour viscéral de la nature et de la forêt en particulier, le pousse à s'installer à Marlotte, près de Fontainebleau, en 1871. Il y trouve son inspiration, sans pour autant oublier sa région natale, et les départements voisins dont il représente les villages pittoresques et les scènes rurales. Dès lors, les commandes ne cessent d'affluer. Réputé et très apprécié de ses contemporains, notamment pour la qualité de ses fusains, Armand Charnay connaît un grand succès aux États-Unis et en Angleterre (la Tate Gallery, le Victoria and Albert Museum, le British Museum ainsi que les musées d'Oxford et de Baltimore possèdent des toiles ou gravures de l'artiste). Décoré de la Légion d'honneur au titre de peintre en 1909, il se détache peu à peu de la peinture en raison de graves problèmes de santé. 
2 En France, le musée Goupil de Bordeaux, le musée d'Art moderne de Saint-Étienne, le musée Déchelette à Roanne et la Bibliothèque nationale de France conservent chacun quelques toiles ou gravures de Charnay tandis que la grande majorité de son œuvre demeure à Charlieu ${ }^{1}$, où il l'avait léguée pour créer un musée à son nom. Les toiles ayant appartenu à l'ancien musée du Luxembourg à Paris et même celle confiée au Louvre sont aujourd'hui introuvables. Quant au panneau intitulé Vue des hauteurs de Passy peint par Charnay pour le palier du grand escalier de l'Hôtel de Ville de Paris, il est dissimulé par des cloisons.

3 Charnay, reconnu comme peintre paysagiste, peuple d'animaux magnifiquement croqués la plupart de ses toiles et laisse aussi de nombreux dessins préparatoires sur ce thème. Cette omniprésence des animaux n'est nullement surprenante si l'on considère que Charnay, hormis ses années d'études à Paris, passa toute sa vie en milieu rural, à Charlieu d'abord, petite ville de quelque 5000 habitants à l'époque, entourée de gros bourgs paysans, puis à Marlotte, aux abords de la grande forêt de Fontainebleau.

\section{Les représentations du cheval dans le fonds Charnay: nombre, typologie, techniques}

4 Dans l'ensemble du fonds Charnay conservé par le musée de Charlieu, la thématique du cheval correspond à 84 œuvres $^{2}$. La grande majorité (65 notices) figurent des chevaux montés pour la chasse ou l'équitation de loisir. Les autres représentations se rapportent à des chevaux attelés à des calèches ( 6 notices), des chevaux de trait ( 9 notices), 3 études anatomiques et un cheval de cirque. La quasi-totalité des œuvres concernées, s'agissant d'un fonds d'atelier, sont des études à la mine de plomb et à l'encre réalisées la plupart du temps sur papier calque. Ce support, très usité par Charnay, s'explique en grande partie par la pratique du " paysage composé » à laquelle il s'adonne tout au long de sa carrière, juxtaposant des éléments d'architecture, des personnages, des animaux, des objets pour recréer des scènes ayant l'apparence du réel. Un même calque regroupe généralement divers petits croquis répondant souvent à un même thème. C'est particulièrement le cas pour les scènes de chasse à courre, (fig. 1) ce qui accentue encore la surreprésentation de cette catégorie. Notons aussi que ces dessins sont toujours de très petites dimensions (fig. 2)... à l'instar des toiles de Charnay d'ailleurs. 
Figure 1

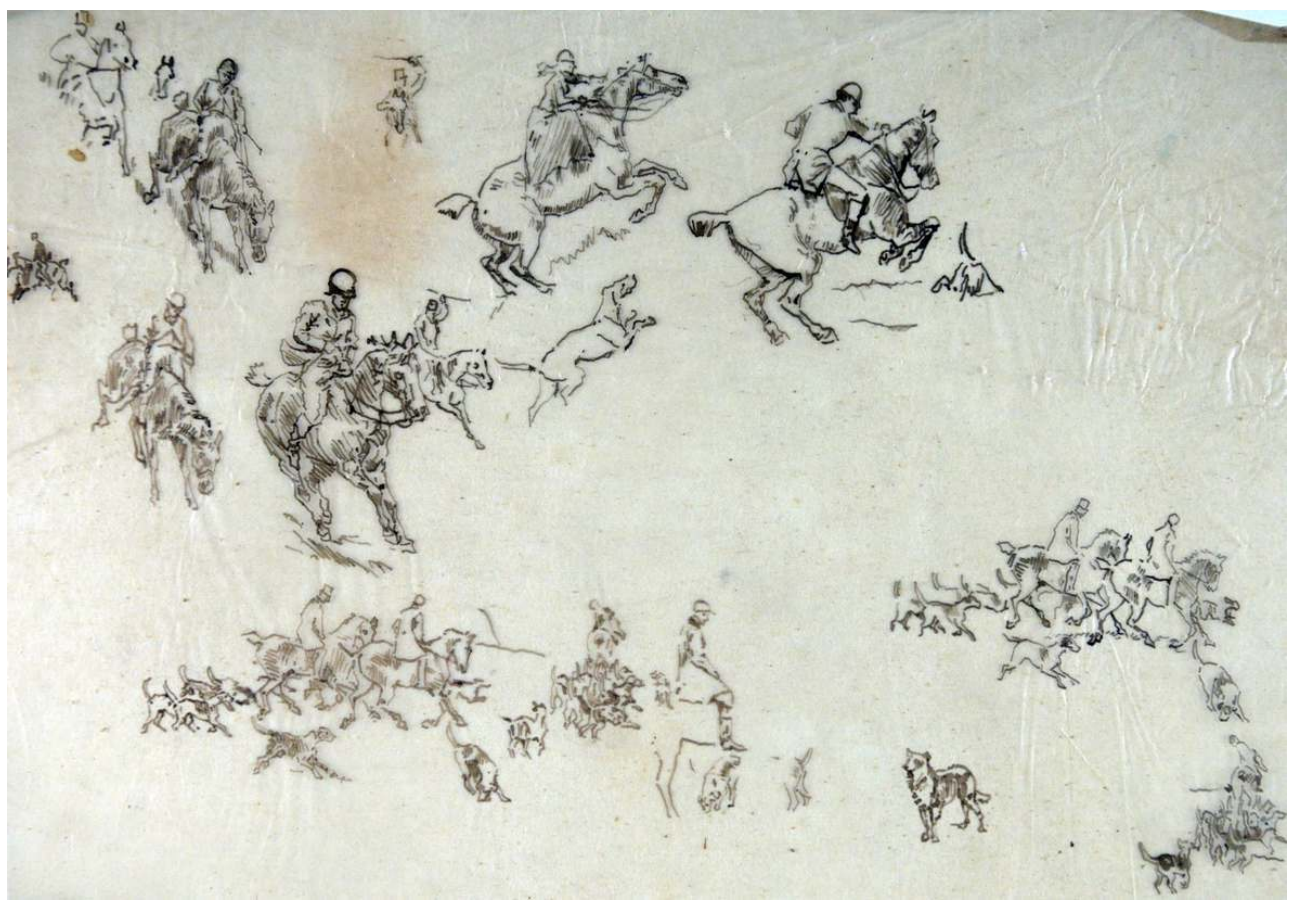

Armand Charnay, Plusieurs scènes de chasse à courre

Coll. Musée de Charlieu MC-CC 98.01.276. @ Musée de Charlieu.

Figure 2

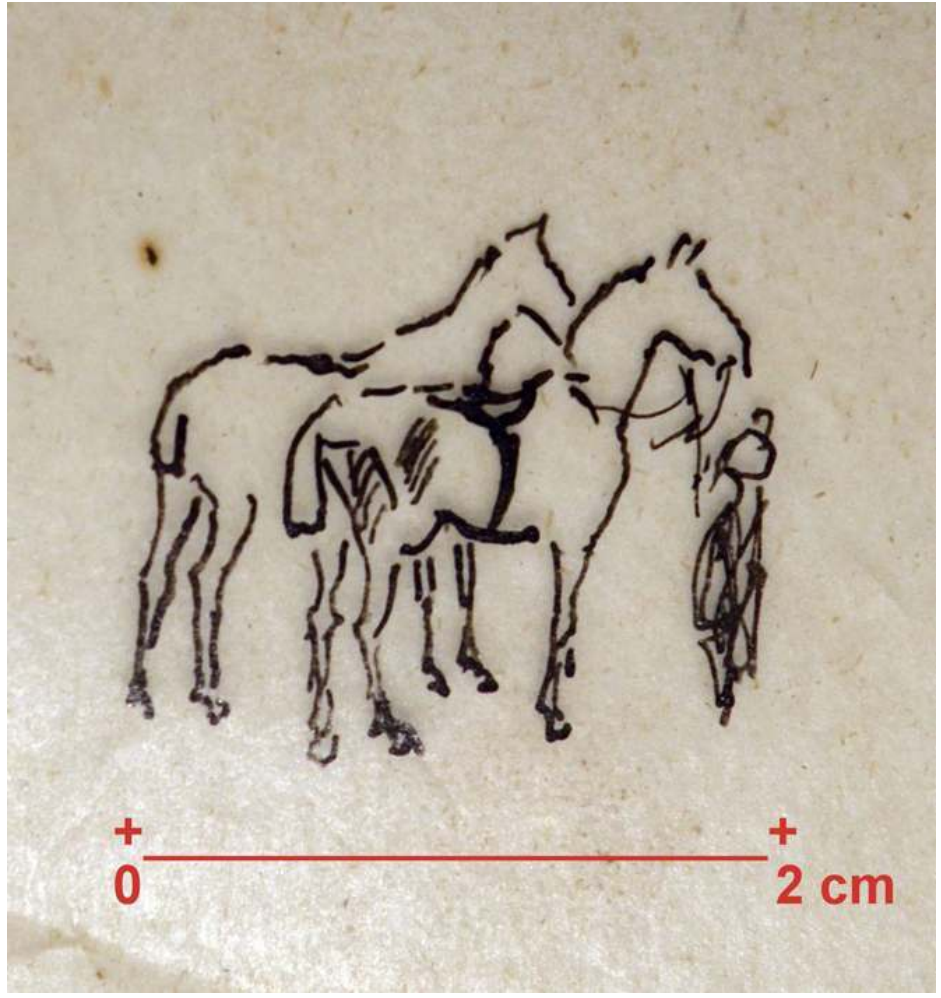

Armand Charnay, Plusieurs scènes de chasse à courre, détail.

Coll. Musée de Charlieu MC-CC 98.01.252. (c) Musée de Charlieu. 


\section{Lecture en creux de la représentation équine dans le fonds Charnay}

5 Une fois ces différentes catégories de représentations énumérées et avant de revenir en détail sur chacune d'elles, livrons-nous à une lecture en creux en examinant les types de chevaux absents de l'œuvre de Charnay, par comparaison avec le travail d'autres artistes sur ce même sujet.

\section{Chevaux de concours hippiques}

Il semble bien que Charnay ne se soit pas du tout intéressé aux chevaux de courses qui furent un sujet de prédilection de la part de nombreux artistes : il n'est que de citer Henri de Toulouse-Lautrec, Edgar Degas, Alfred de Dreux, Albrecht Adam pour les plus connus. La deuxième moitié du XIX ${ }^{e}$ siècle et l'anglomanie ambiante dans la haute société furent pourtant très propices à ce genre de représentations.

\section{Chevaux de trait citadins}

7 Les chevaux de trait citadins sont eux aussi absents, à une exception près sur laquelle nous reviendrons dans quelques instants, alors qu'ils sont omniprésents chez un peintre proche? voisin, plus jeune d'une génération, Maurice Montet $^{3}$, avec ses chevaux tirant des charrettes pour le transport et la livraison des marchandises en ville. À l'époque de Charnay, les chevaux sont pourtant très nombreux, comme l'attestent les photographies et les cartes postales, à effectuer ce genre de tâches dans les rues des villes. C'est d'ailleurs en priorité pour ces équidés-là, trimant sous les coups sur le pavé parisien qu'est créée, en 1845 , la Société protectrice des animaux. La seule représentation de cheval commissionnaire que nous possédons dans le fonds Charnay est intitulée Une rue de Châteauneuf sous la pluie (fig. 3). 
Figure 3

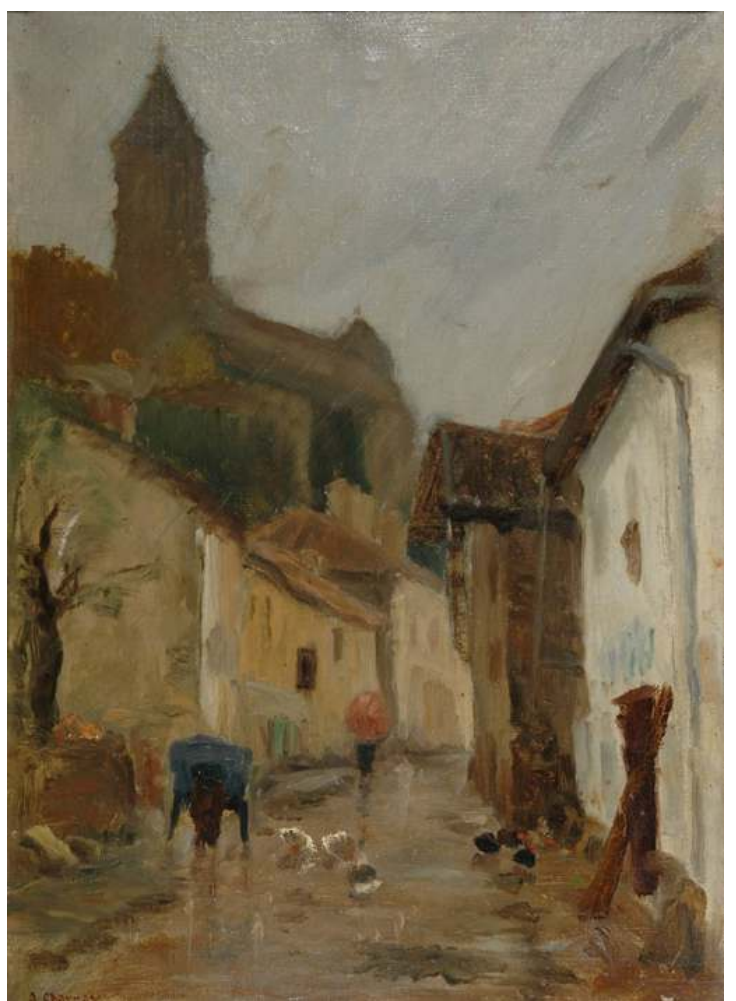

Armand Charnay, Une rue de Châteauneuf-sur-Sornin par la pluie.

Coll. Musée de Charlieu MC-CC 97.01.101. @ Musée de Charlieu.

\section{Scènes équines pittoresques}

8 Le fonds Charnay ne recèle pas non plus de chevaux de trait représentés au repos dans une cour de ferme ou attachés devant un bâtiment comme ceux de Giovanni Fattori ${ }^{4}$. Pas non plus e chevaux à l'écurie à la façon d'un Géricault, ou de marché aux chevaux. Pas même de scènes de ferrage, si représentatives du travail rural à la fin du XIX ${ }^{e}$ siècle, ni de chevaux utilisés pour débarder en forêt de Fontainebleau, lutter contre l'incendie ou travailler à l'exploitation des carrières. À propos de scènes pittoresques, Charnay se rendant en villégiature à Yport en Normandie, on aurait pu s'attendre, comme chez son confrère et voisin de Marlotte, Charles Jacque ${ }^{5}$, à des représentations de chevaux goémoniers... qui sont elles aussi absentes, au même titre que les chevaux utilisés pour la pêche aux équilles.

9 Enfin, Charlieu étant toute proche du canal du Centre, il ne manquait pas de nombreux chevaux tirant les lourdes péniches comme les a immortalisés, quelques décennies plus tard le film La Belle Marinière ${ }^{6}$, tourné dans cette région, avec le cheval Tombouctou.

\section{Les chevaux du fonds Charnay}

10 Attachons-nous maintenant aux différentes représentations de chevaux rencontrées dans le fonds Charnay, dans l'ordre inverse de leur nombre. 


\section{Le cheval de cirque}

11 Cette unique et minuscule représentation (fig. 4) est peut-être à rapprocher de quelques dessins de Charnay mettant en scène des saltimbanques exhibant des animaux tels que singes, ours, chiens savants... En cette fin du XIX ${ }^{\mathrm{e}}$ siècle, la veine «bohémienne » est à la mode parmi les artistes.

Figure 4

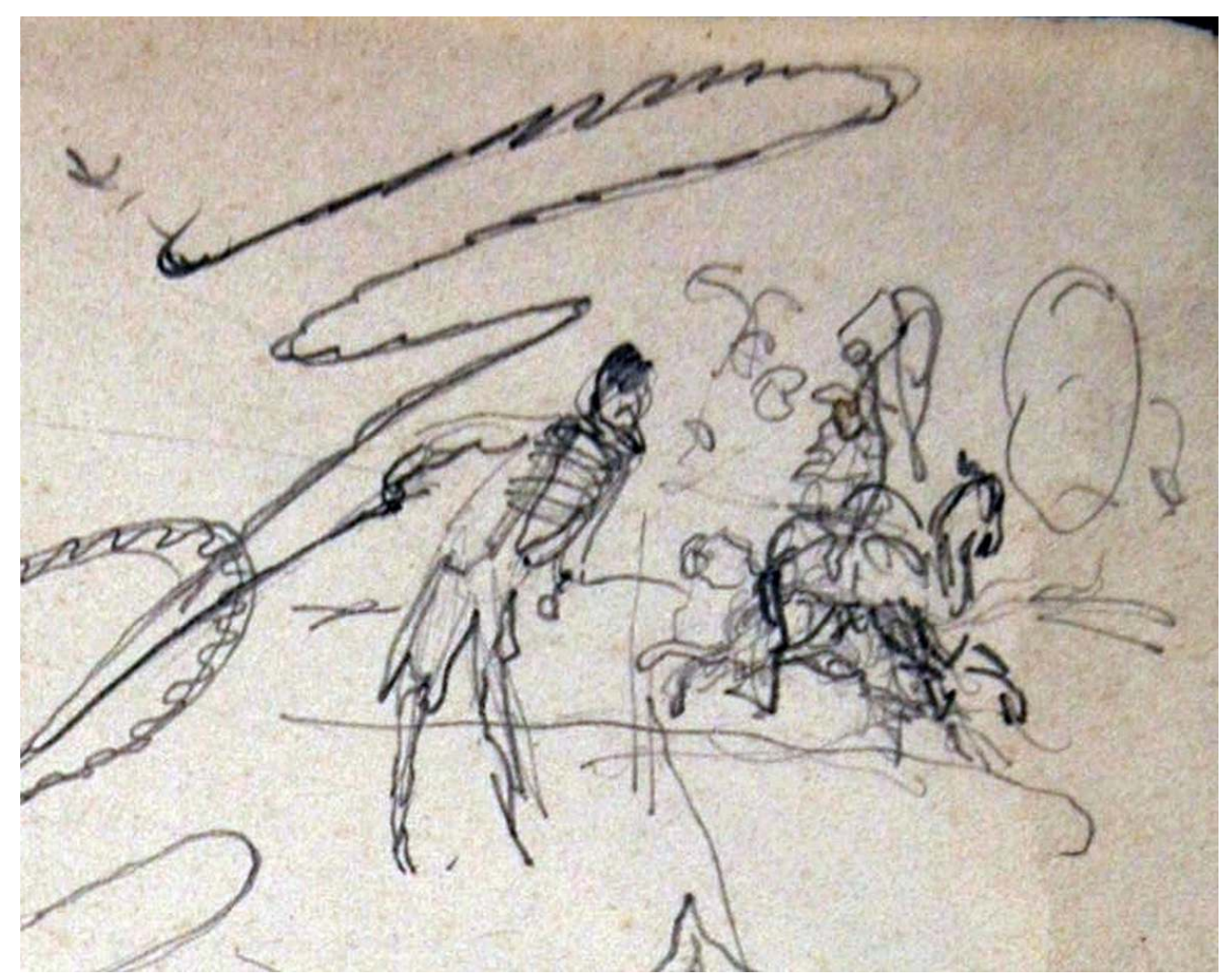

Armand Charnay, Études.

Coll. Musée de Charlieu MC-CC 99.01.147. ( ) Musée de Charlieu.

\section{Les études anatomiques}

Ces petits croquis traduisent bien la volonté de Charnay de représenter les animaux de façon très réaliste, avec un grand souci d'exactitude. Ainsi, le calque qui porte le numéro d'inventaire 97.01.608 regroupe-t-il une étude de pied avec balzane, différentes études de chevaux vus de dos, de trois-quarts ou de côté (fig. 5, fig. 6, fig. 7). 
Figure 5

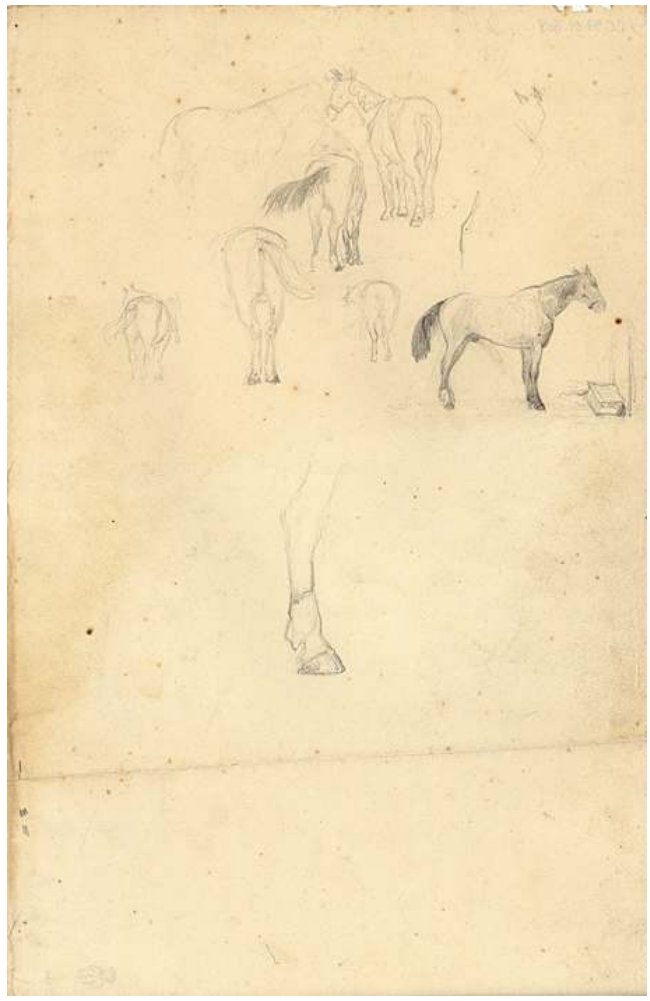

Armand Charnay, Études de cheval.

Coll. Musée de Charlieu MC-CC 97.01.608. ㅇ Musée de Charlieu. 
Figure 6

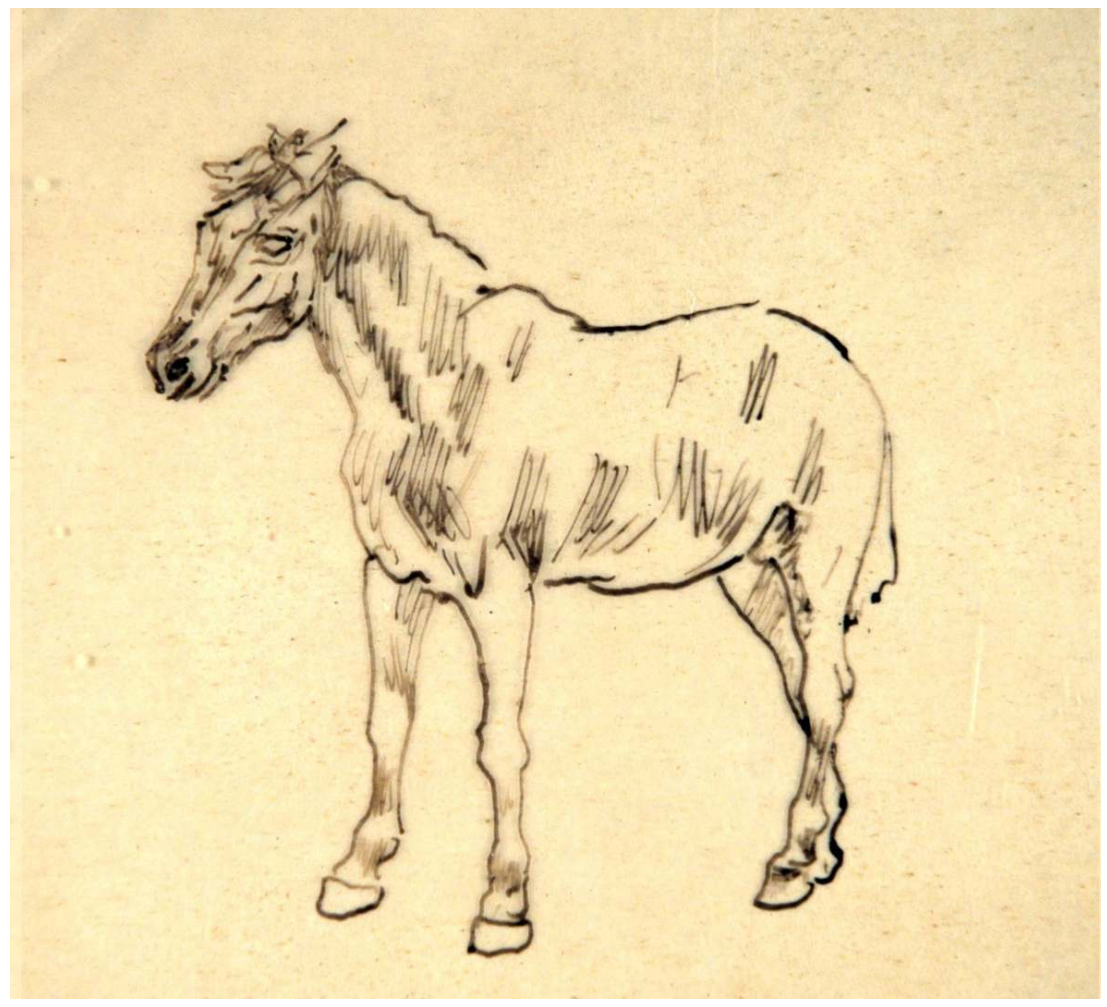

Armand Charnay, Étude de cheval.

Coll. Musée de Charlieu MC-CC 98.01.231. (c) Musée de Charlieu. 
Figure 7

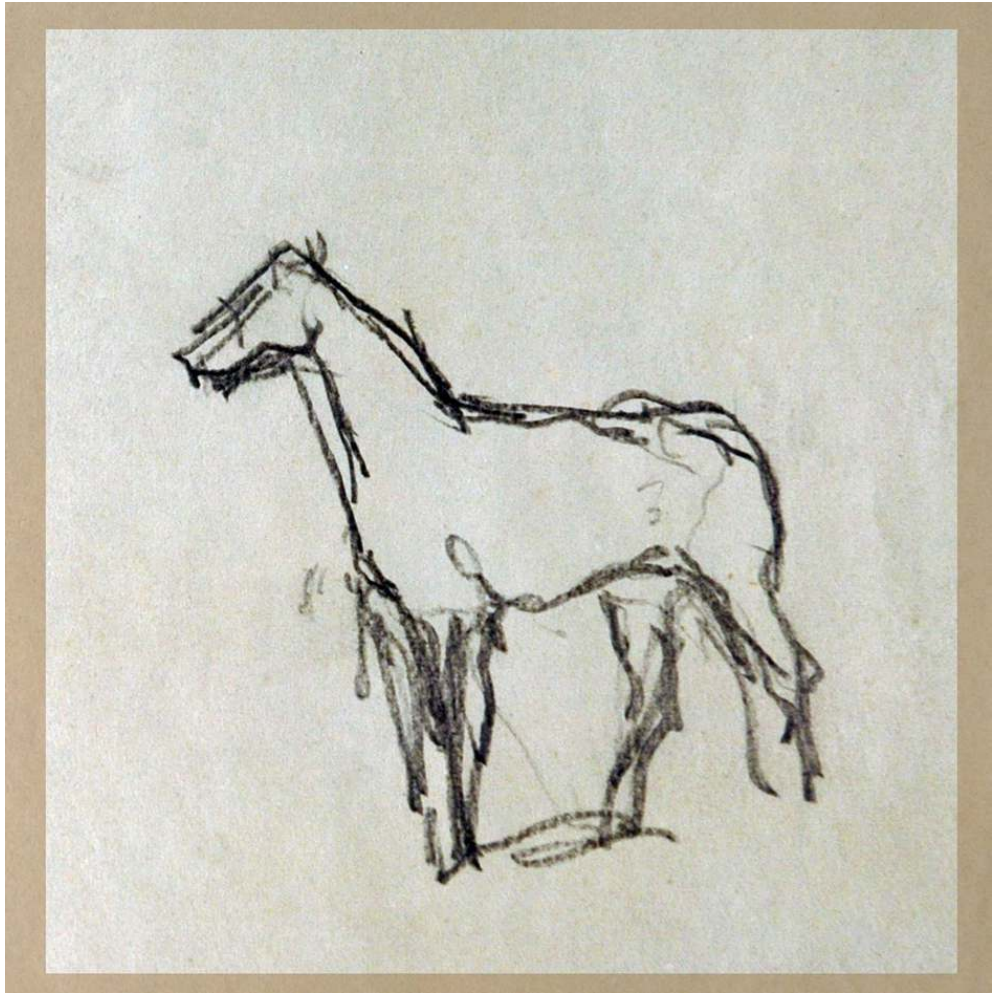

Armand Charnay, Cheval.

Coll. Musée de Charlieu MC-CC 99.01.96. ㄷ Musée de Charlieu.

\section{Les chevaux attelés à des calèches}

13 Avec eux, nous entrons de plain-pied dans l'environnement social de Charnay : la dame chapeautée conduisant son attelage (fig. 8) pourrait tout à fait être Mme Charnay mère, femme du notaire et ancien maire de Charlieu que fut le père de l'artiste. Ces représentations nous rappellent qu'au XIX ${ }^{\mathrm{e}}$ siècle, la voiture à cheval se généralise dans les villes et sur les routes, avec des modèles diversifiés suivant les fonctions du transport hippomobile. 
Figure 8

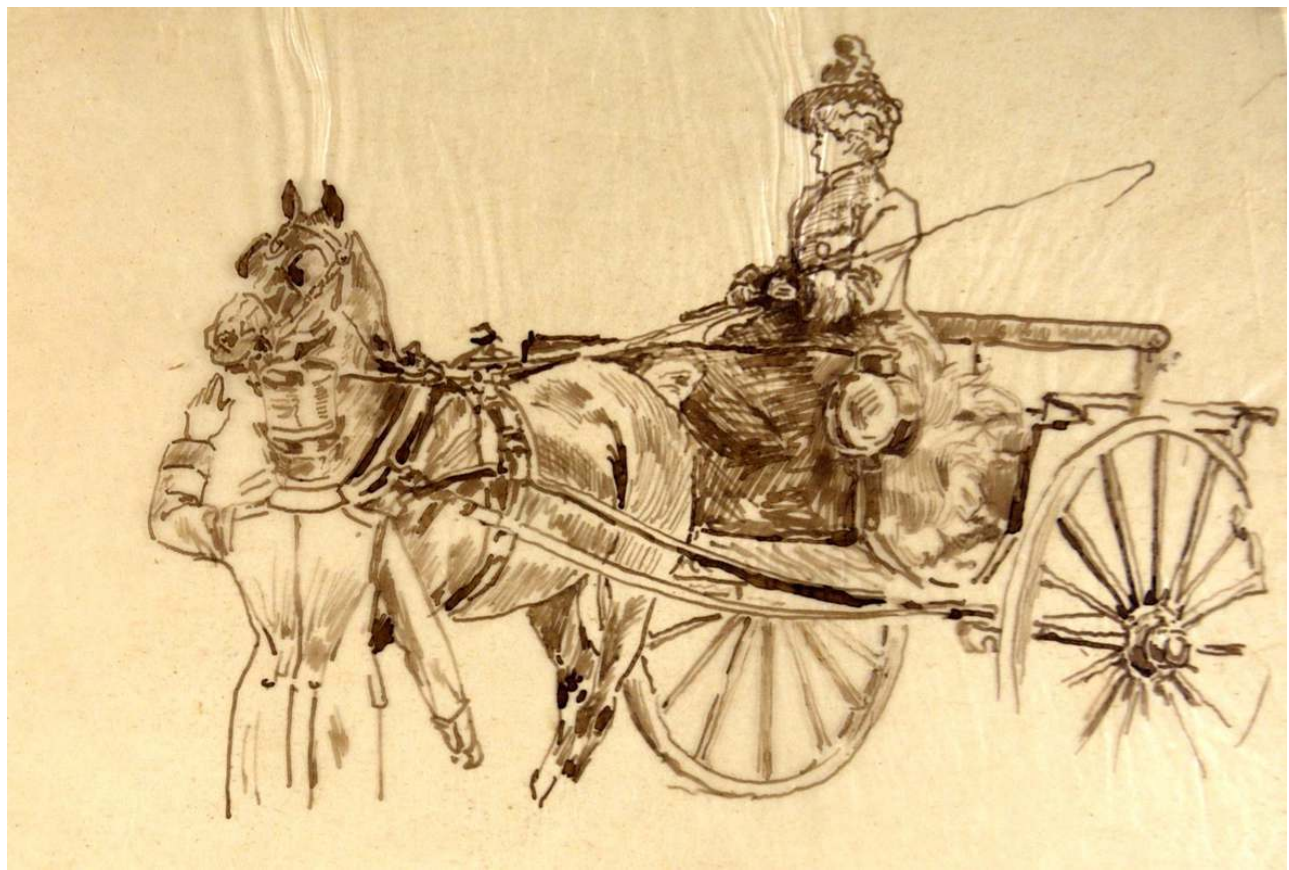

Armand Charnay, Femme dans une calèche.

Coll. Musée de Charlieu MC-CC 98.01.283. @ Musée de Charlieu.

\section{Les chevaux de trait}

Figure 9

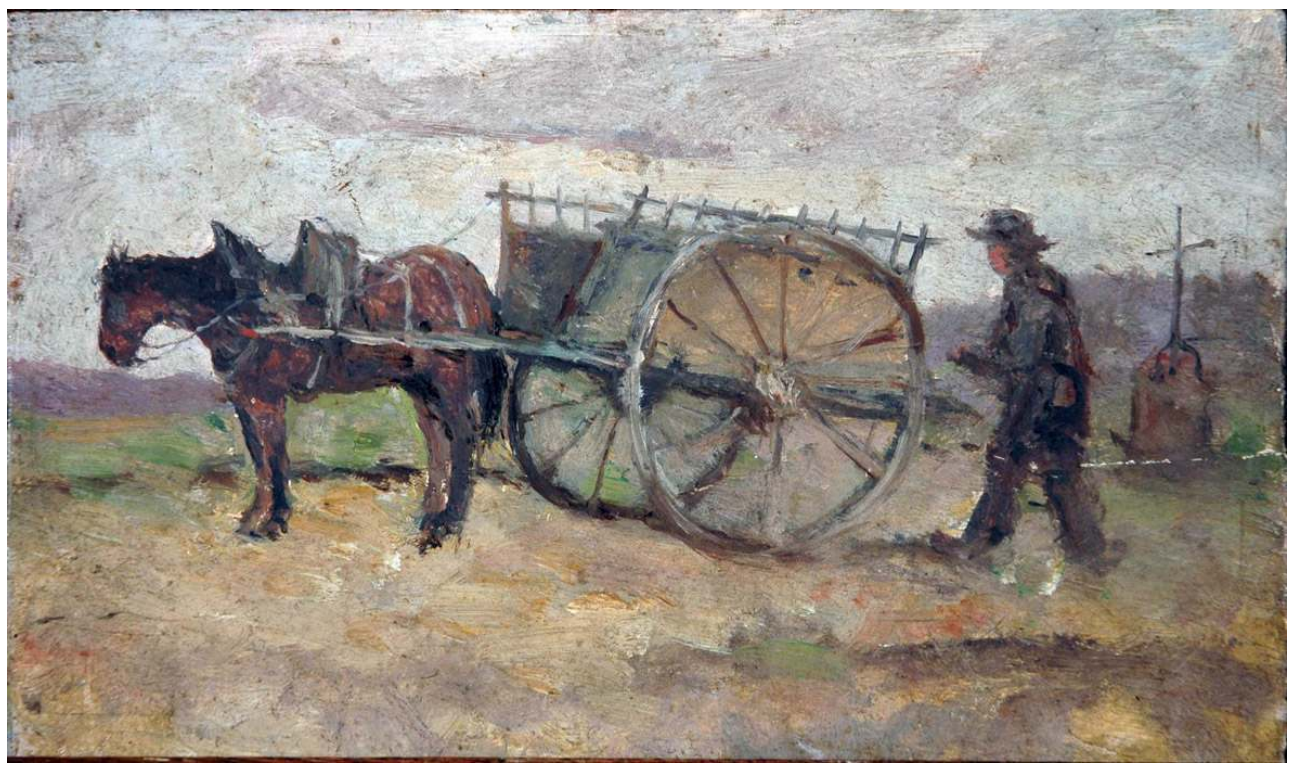

Armand Charnay, Paysan, son cheval et sa charrette.

Coll. Musée de Charlieu MC-CC 99.01.69. @ Musée de Charlieu. 
Figure 10

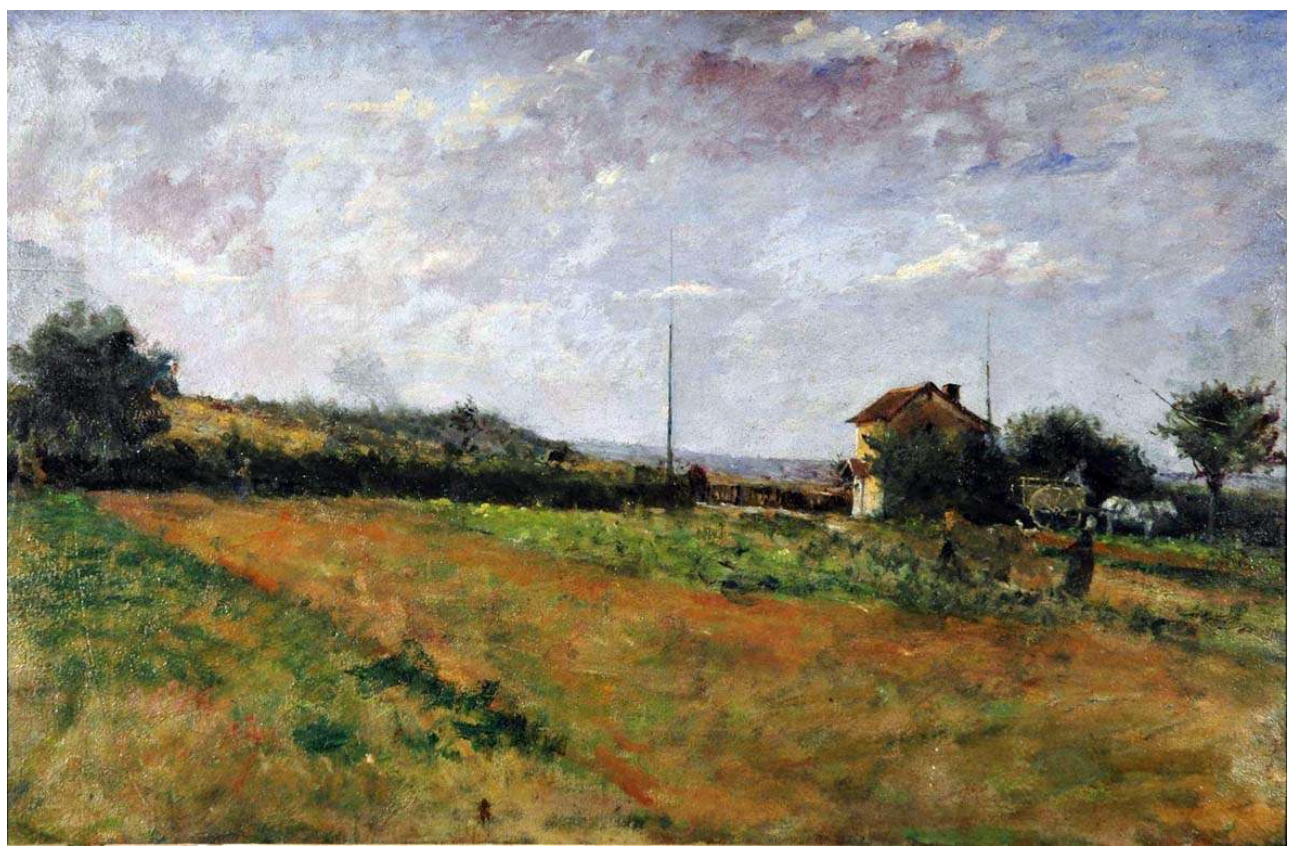

Armand Charnay, Paysage avec potager, maison et charrette.

Coll. Musée de Charlieu MC-CC 97.01.32. ( ) Musée de Charlieu.

14 Les chevaux de trait utilisés pour l'agriculture sont à peine plus nombreux à être représentés : à la différence des œuvres citées précédemment qui sont toutes des dessins à l'encre ou à la mine de plomb, nous avons cette fois-ci deux huiles représentant des chevaux attelés à des charrettes (fig. 9, fig. 10) et un très beau fusain avec des rehauts de craie blanche (fig. 11). Notons au passage que Charnay est l'auteur d'un ouvrage théorique sur cette technique qui fit longtemps référence. 
Figure 11

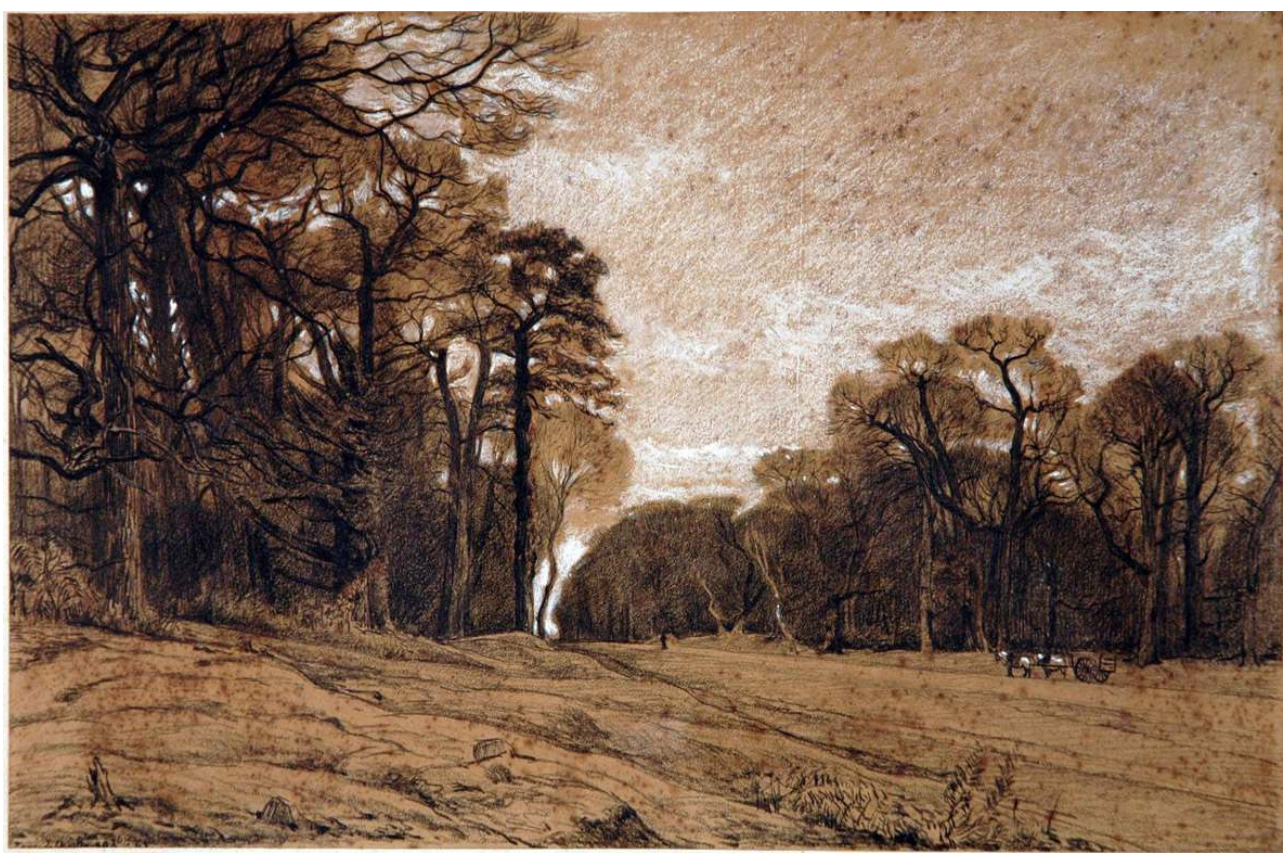

Armand Charnay, Pavé de Chailly.

Coll. Musée de Charlieu MC-CC 97.01.477. ( ) Musée de Charlieu.

15 Mais ce sont les dessins qui sont les plus intéressants : celui, par exemple, d'un cheval portant collier et œillères (fig. 12) et mesurant... $2 \mathrm{~cm}$ sur $1 \mathrm{~cm}$ ! 
Figure 12

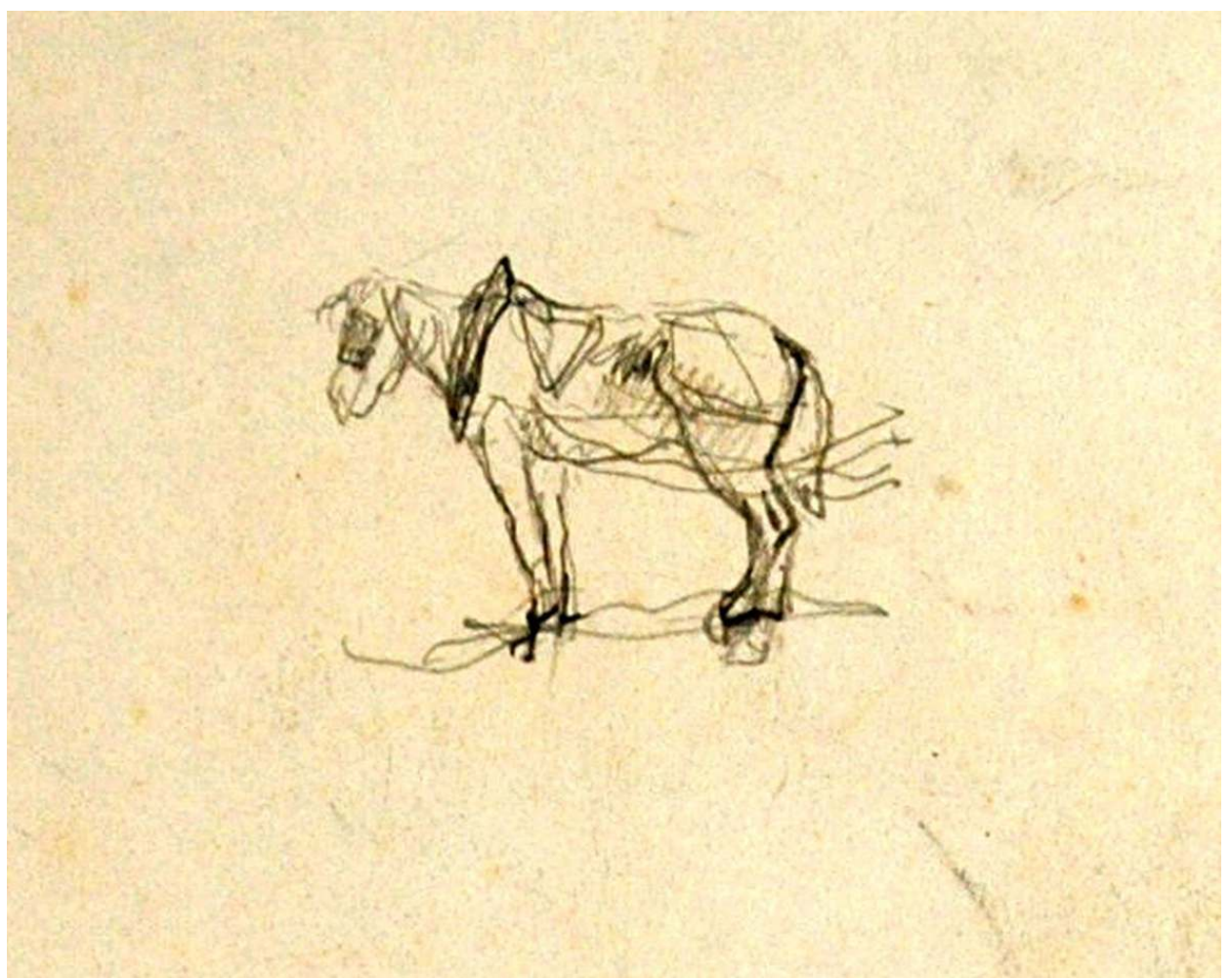

Armand Charnay, Études.

Coll. Musée de Charlieu MC-CC 99.01.145. (c) Musée de Charlieu.

Plusieurs autres dessins illustrent le dur labeur des champs dans des scénettes expressives où cheval, chien et homme paraissent harassés, courbés par l'effort ou luttant contre les éléments (fig. 13, fig. 14, fig. 15). Là encore, il s'agit au total de 9 représentations seulement. 
Figure 13

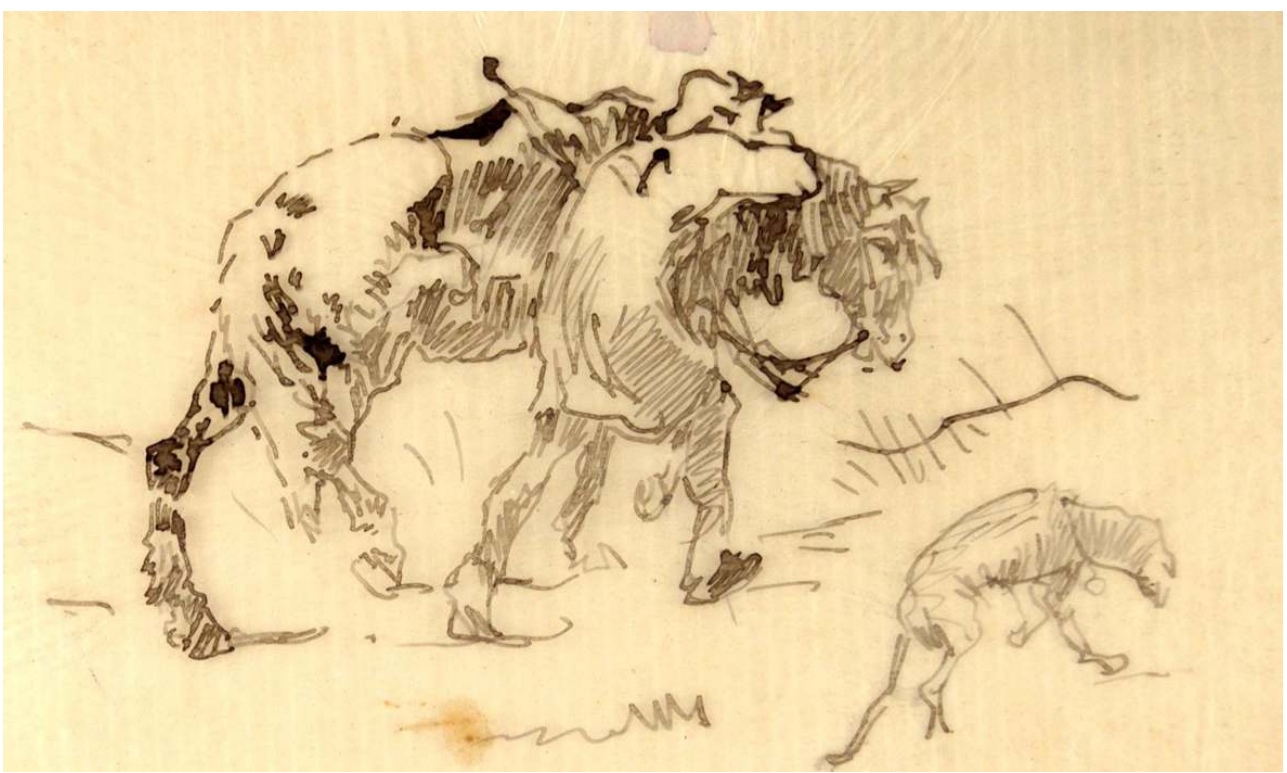

Armand Charnay, Études de paysan avec son cheval.

Coll. Musée de Charlieu MC-CC 98.01.23. (c) Musée de Charlieu.

\section{Figure 14}

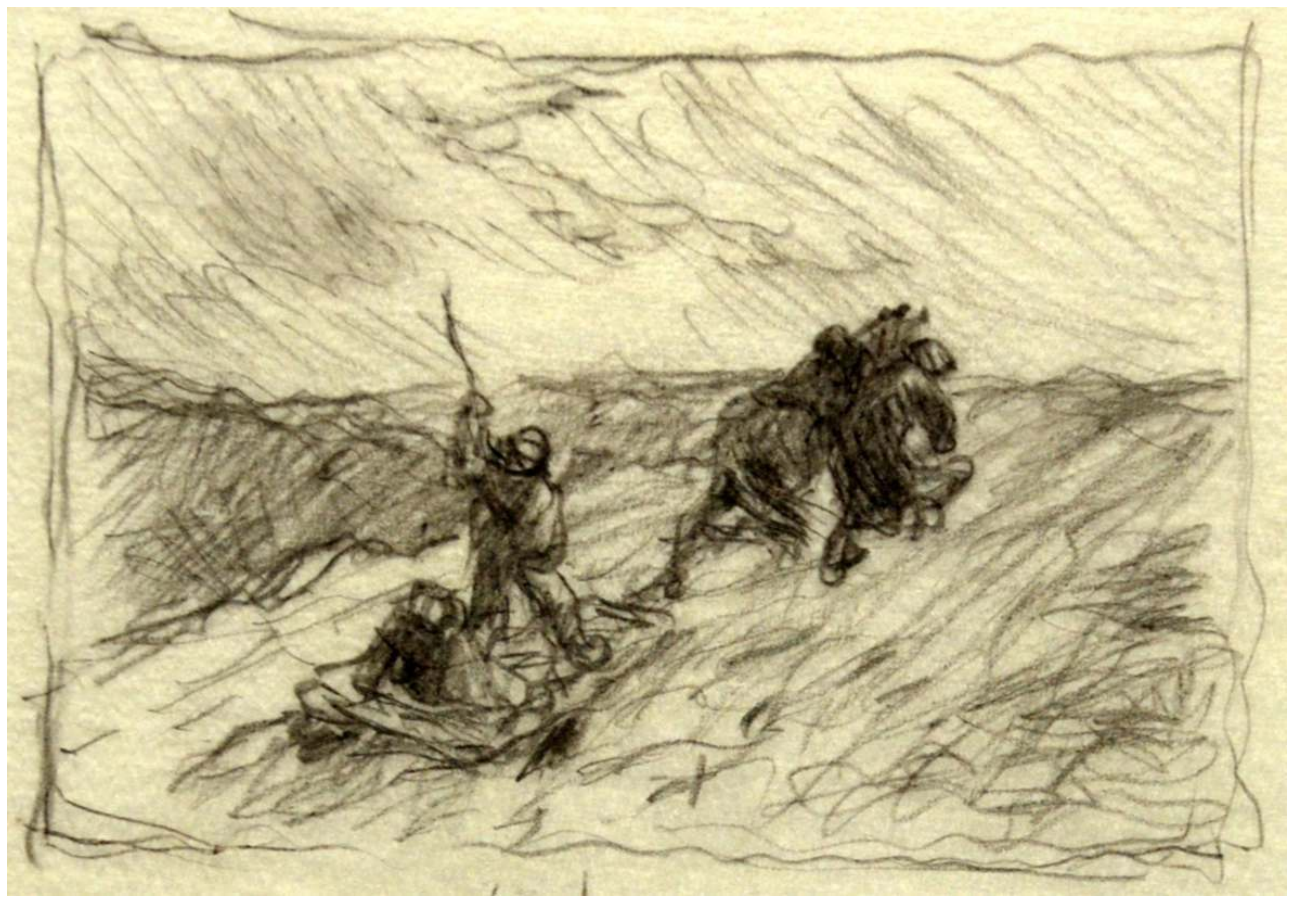

Armand Charnay, Étude de scène paysanne.

Coll. Musée de Charlieu MC-CC 98.01.16. (C) Musée de Charlieu. 
Figure 15

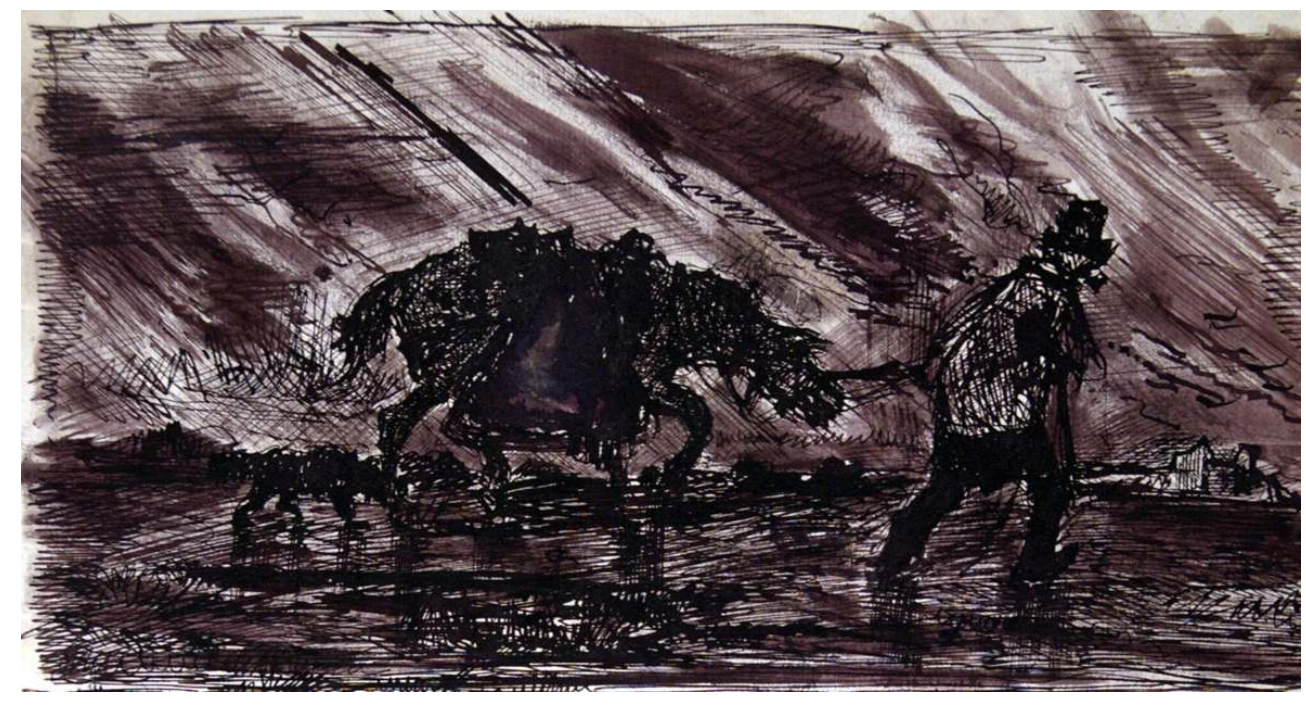

Armand Charnay, Étude d'homme et son cheval sous un orage.

Coll. Musée de Charlieu MC-CC 97.01.713. (c) Musée de Charlieu.

\section{Les chevaux de loisir}

Chevaux de vénerie montée et chevaux d'équitation représentent donc la très grande majorité des sujets. Ils peuplent de petites scènes, inlassablement travaillées, parfois regroupées densément sur la même feuille de calque, dans lesquelles Charnay représente les protagonistes avec précision et justesse et fait montre d'une grande maîtrise technique (fig. 16, fig. 17, fig. 18). 
Figure 16

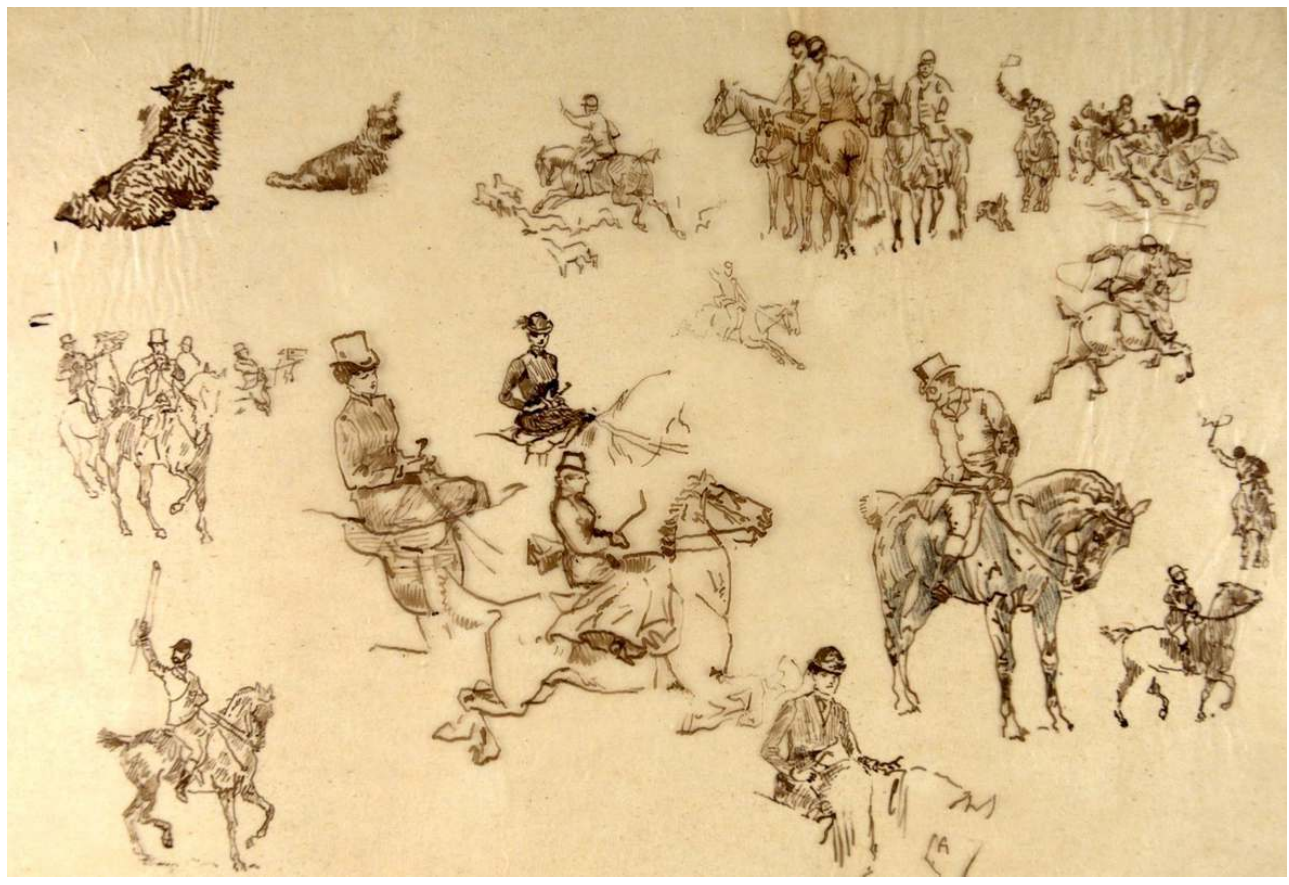

Armand Charnay, Scènes de chasse à courre.

Coll. Musée de Charlieu MC-CC 98.01.286. (C) Musée de Charlieu.

Figure 17

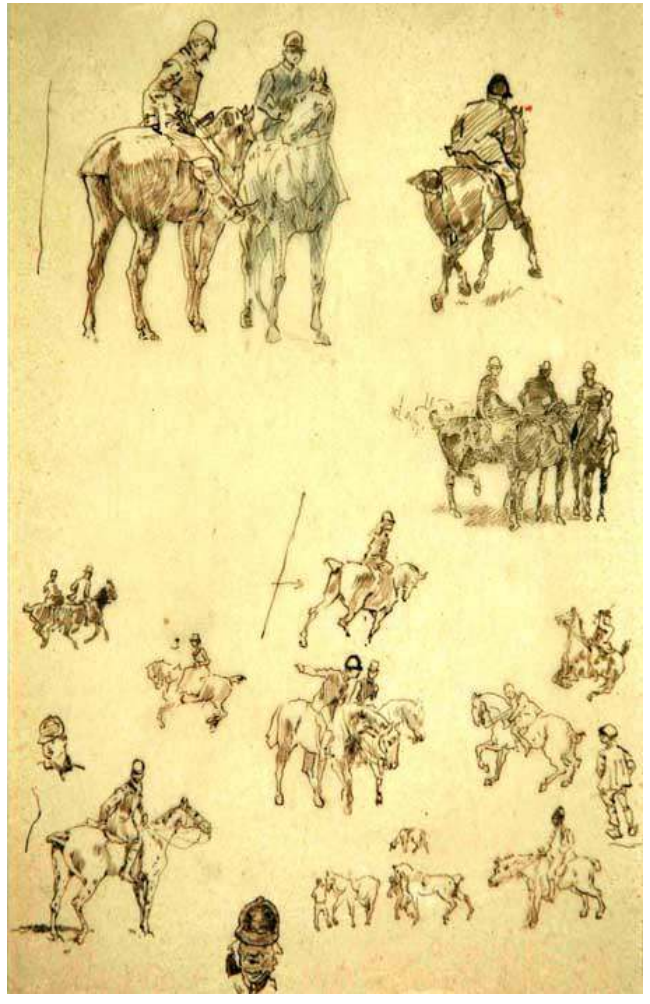

Armand Charnay, Études de cavaliers de chasse à courre.

Coll. Musée de Charlieu MC-CC 98.01.281. ( ) Musée de Charlieu. 
Figure 18

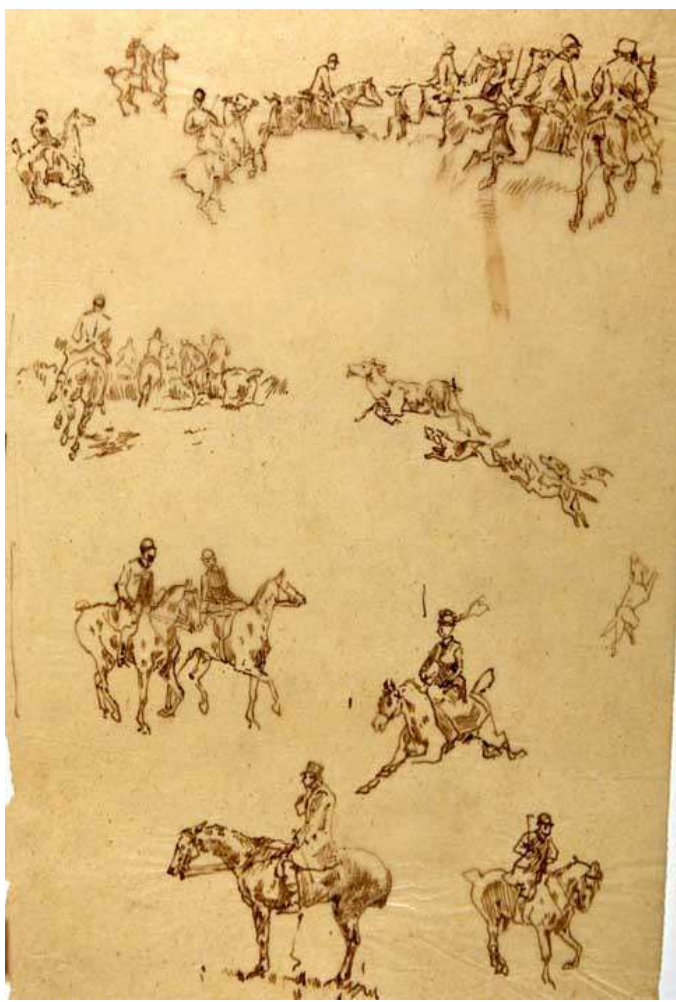

Armand Charnay, Scènes de chasse à courre.

Coll. Musée de Charlieu MC-CC 98.01.280. ( Musée de Charlieu.

Dans l'un comme dans l'autre cas, chasse ou équitation, il s'agit des loisirs de l'aristocratie ou de la grande bourgeoisie, d'occupations qui sont aussi symboles de prestige et expression d'un rang social dans un milieu où l'oisiveté est un art de vivre. Chez Charnay, la vénerie montée est représentée dans toute sa pompe, avec équipages en livrées, " boutons ${ }^{7}$ ", piqueurs, veneurs, meutes de chiens, chevaux... Chacun de ces groupes est présent en nombre car cette activité est savamment orchestrée et codifiée et chaque participant - y compris quelques femmes - joue son rôle. Des équipements particuliers apparaissent : trompes de chasse, bombes d'équitation, selles d'amazones, fouets... On chasse aussi en haut-de-forme et monocle ! (fig. 19) 
Figure 19

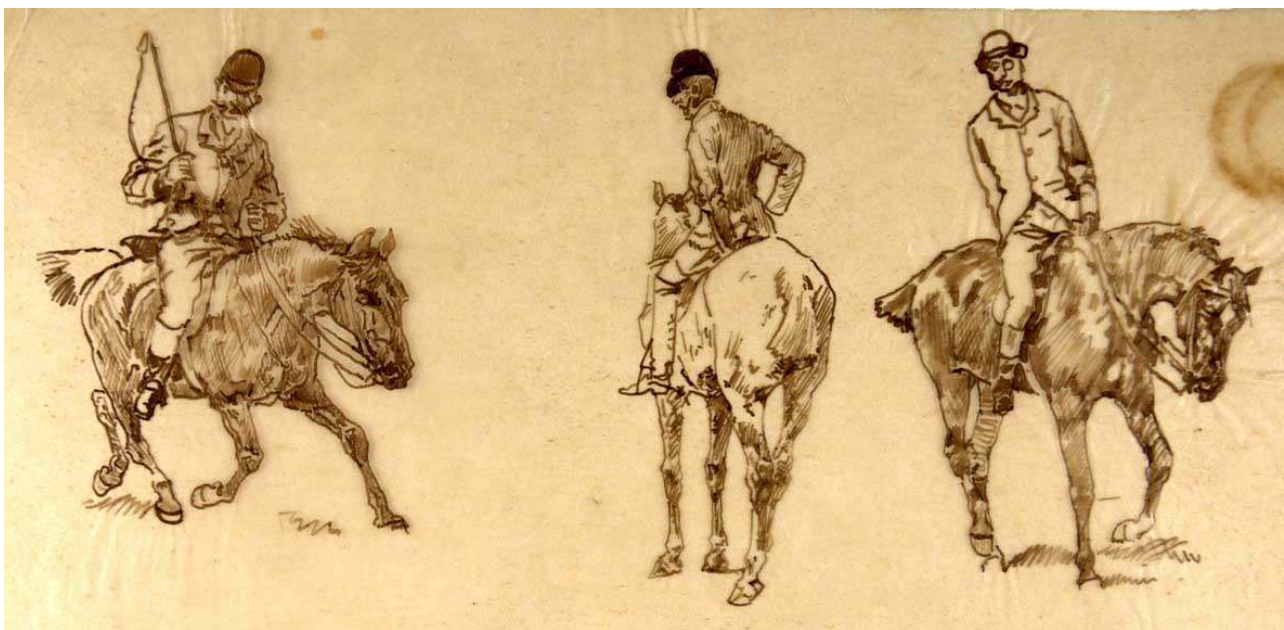

Armand Charnay, Trois cavaliers de chasse à courre.

Coll. Musée de Charlieu MC-CC 98.01.288. @ Musée de Charlieu.

Ici, le cheval est un marqueur social très fort : ces pratiques sont réservées à une élite fortunée qui se met en scène dans une représentation identitaire et mondaine, comme en témoigne le dessin au fusain intitulé La Messe de la Saint-Hubert (fig. 20), la lithographie intitulée Le bac de la ferme (fig. 21), ou encore La leçon d'équitation (fig. 22), tableau présenté au Salon de 1872.

Figure 20

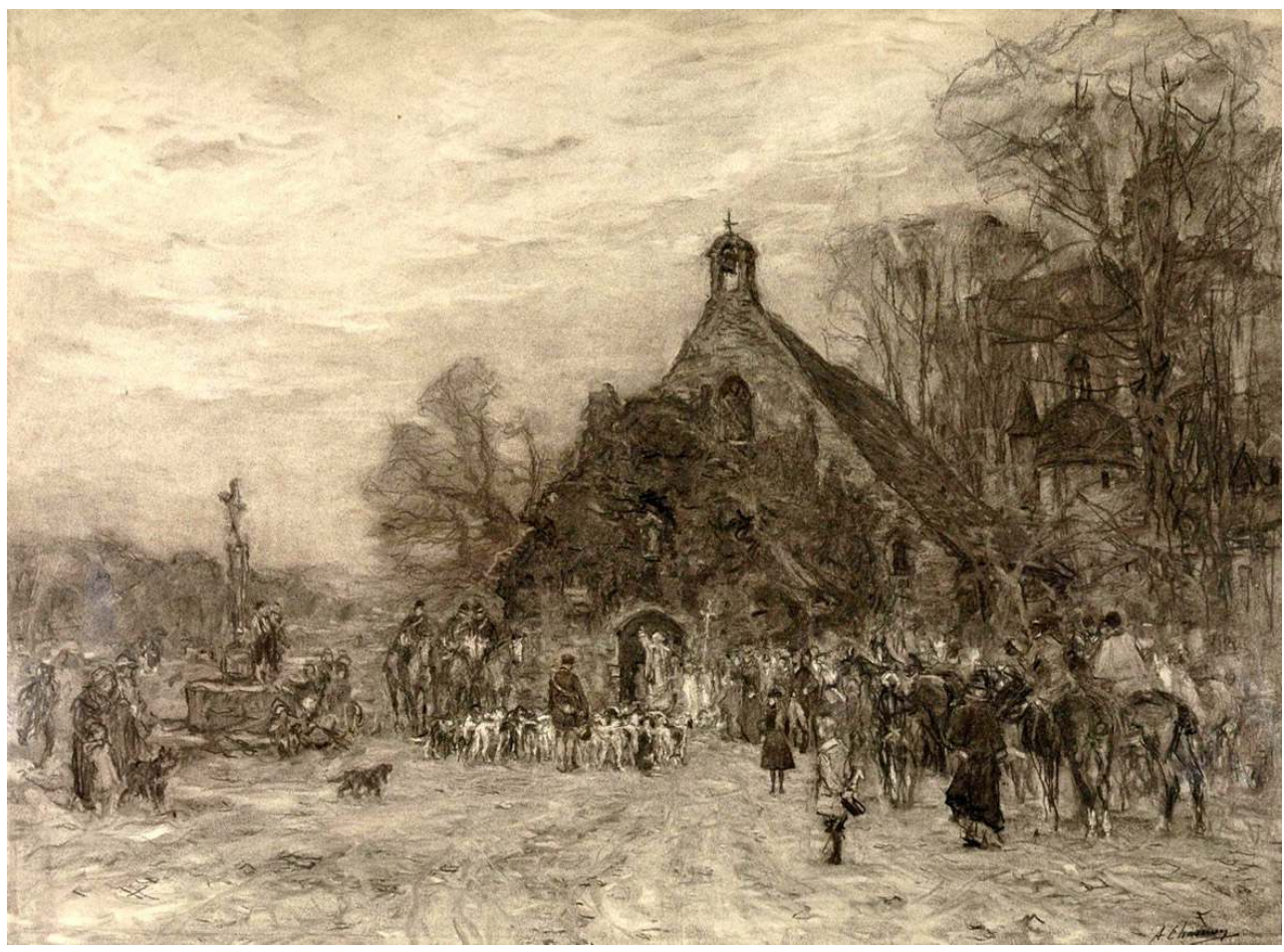

Armand Charnay, La messe de Saint-Hubert.

Coll. Musée de Charlieu MC-CC 97.01.368. @ Musée de Charlieu. 


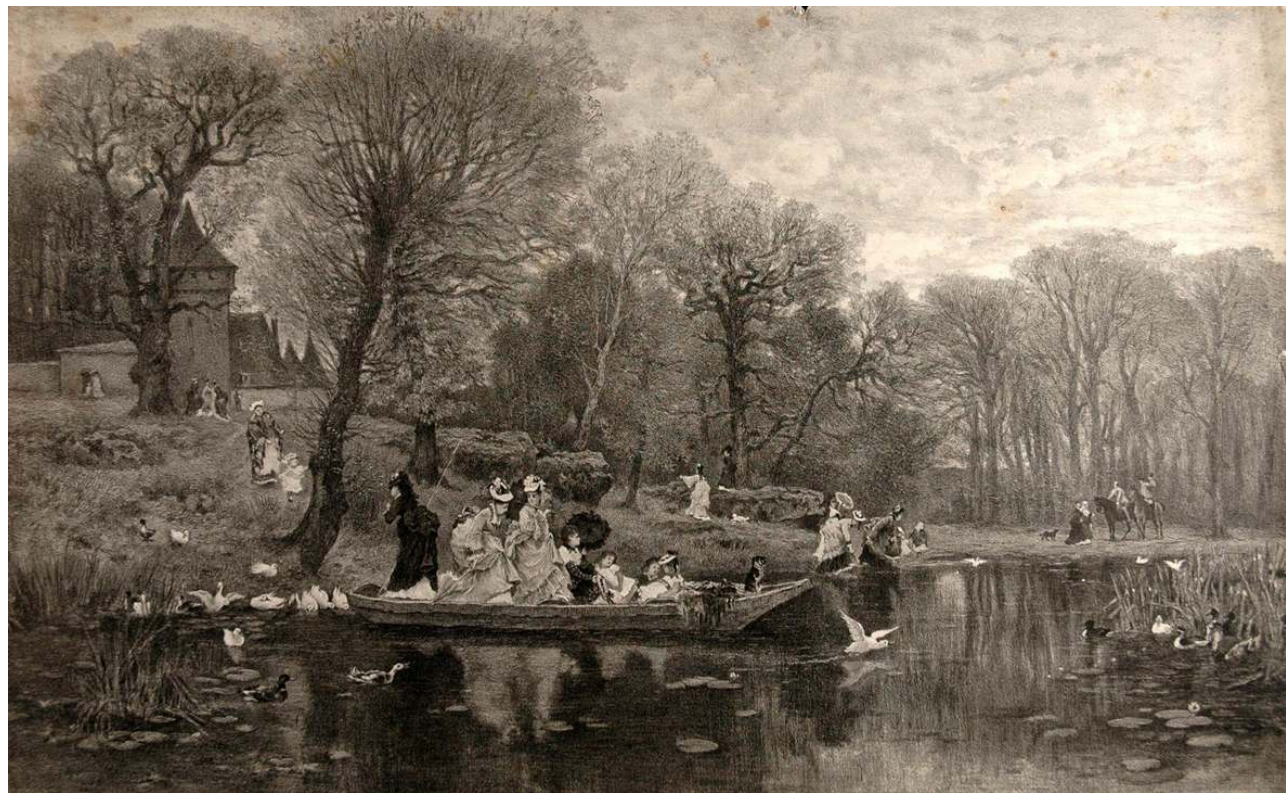

Armand Charnay, Le bac de la ferme.

Coll. Musée de Charlieu MC-CC 99.01.10. ㅇ Musée de Charlieu.

Figure 22

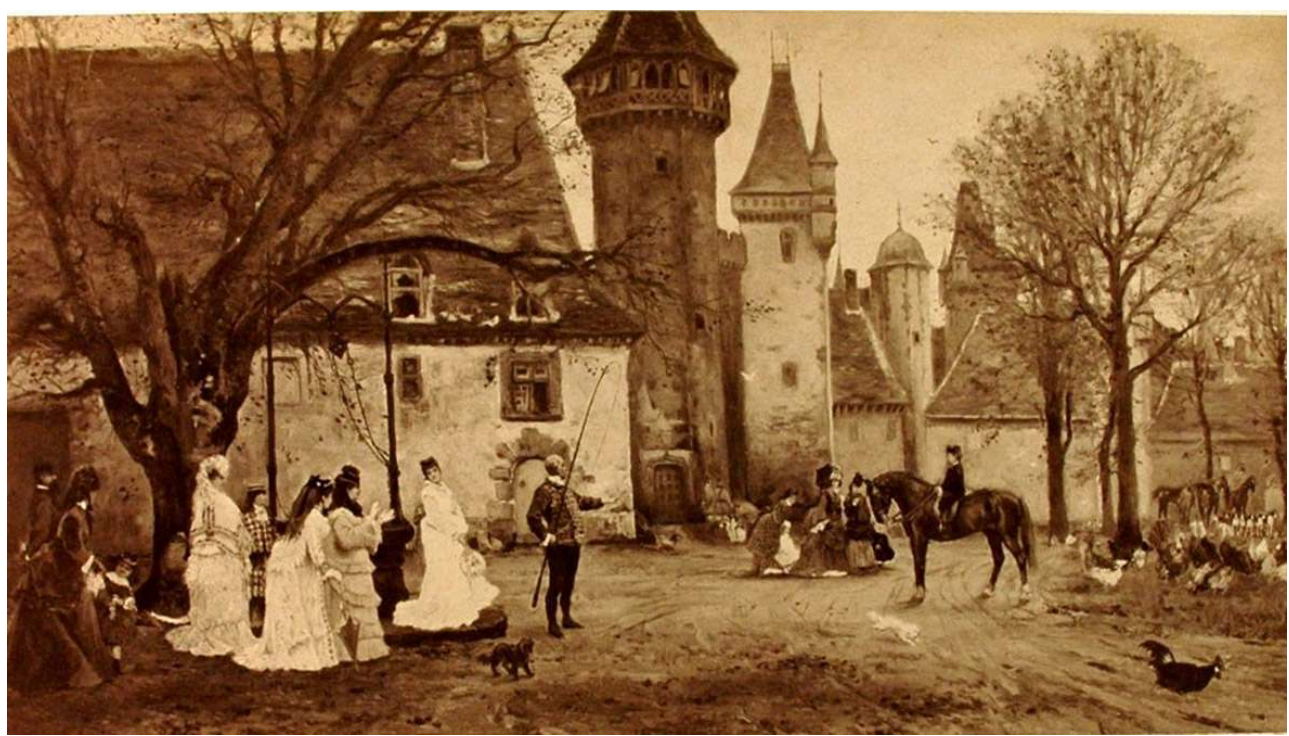

Armand Charnay, La leçon d'équitation

Coll. Musée de Charlieu MC-CC 99.01.33. @ Musée de Charlieu.

\section{Les chevaux de chasse à courre de Charnay : quelle signification?}

Comment interpréter cette prédominance des chevaux de chasse «à cor et à cri » dans l'œuvre de Charnay alors que lui-même ne pratiqua pas ce type de chasse mais la chasse à tir entre notables accompagnés de leurs chiens, plus conforme à son statut social de 
bourgeois aisé et dont il a laissé un beau récit publié dans La Chasse illustrée $e^{8}$. Dans un premier temps, on peut penser qu'il s'agit, d'une certaine façon, de "répondre à la demande ». Représenter les boutons, les maîtres d'équipage, les relais de chiens fréquentant la forêt de Fontainebleau pouvait permettre à Charnay d'attirer sur sa peinture le regard d'une clientèle fortunée, se contemplant elle-même avec satisfaction dans une de ses activités favorites. Toutefois, connaissant la personnalité de Charnay, cette hypothèse se révèle peu vraisemblable ou, du moins, secondaire. Charnay était suffisamment fortuné pour ne pas être contraint à vendre ses œuvres et il refusa souvent avec véhémence de travailler sur commande. Alors?

\section{Le cheval de chasse à courre : porteur symbolique d'aspirations sociales}

Dans le cas de Charnay, tout porte à croire que ces multiples représentations de scènes de chasse à courre sont le révélateur - au sens photographique du terme - d'un désir d'ascension sociale, d'une identification à un groupe social considéré comme supérieur au sien, de son admiration, pour ne pas dire fascination, pour un mode de vie particulier. Nous savons que Charnay aimait fréquenter châteaux et châtelains. Même si, à son époque, les barrières entre classes sociales étaient très étanches, il était sans doute admis à côtoyer les "gens des châteaux " grâce à sa culture, considérable, son esprit, son éducation. C'est ainsi que Charnay représenta les châteaux de Lassalle, de Sansac, de Châteaumorand, de Beauvernay... À Charlieu, il entretenait des liens particuliers avec les propriétaires du château de Gatellier. Il dessina et peignit à de multiples reprises la grille d'entrée de celui-ci : quel symbole! (fig. 23) 
Figure 23

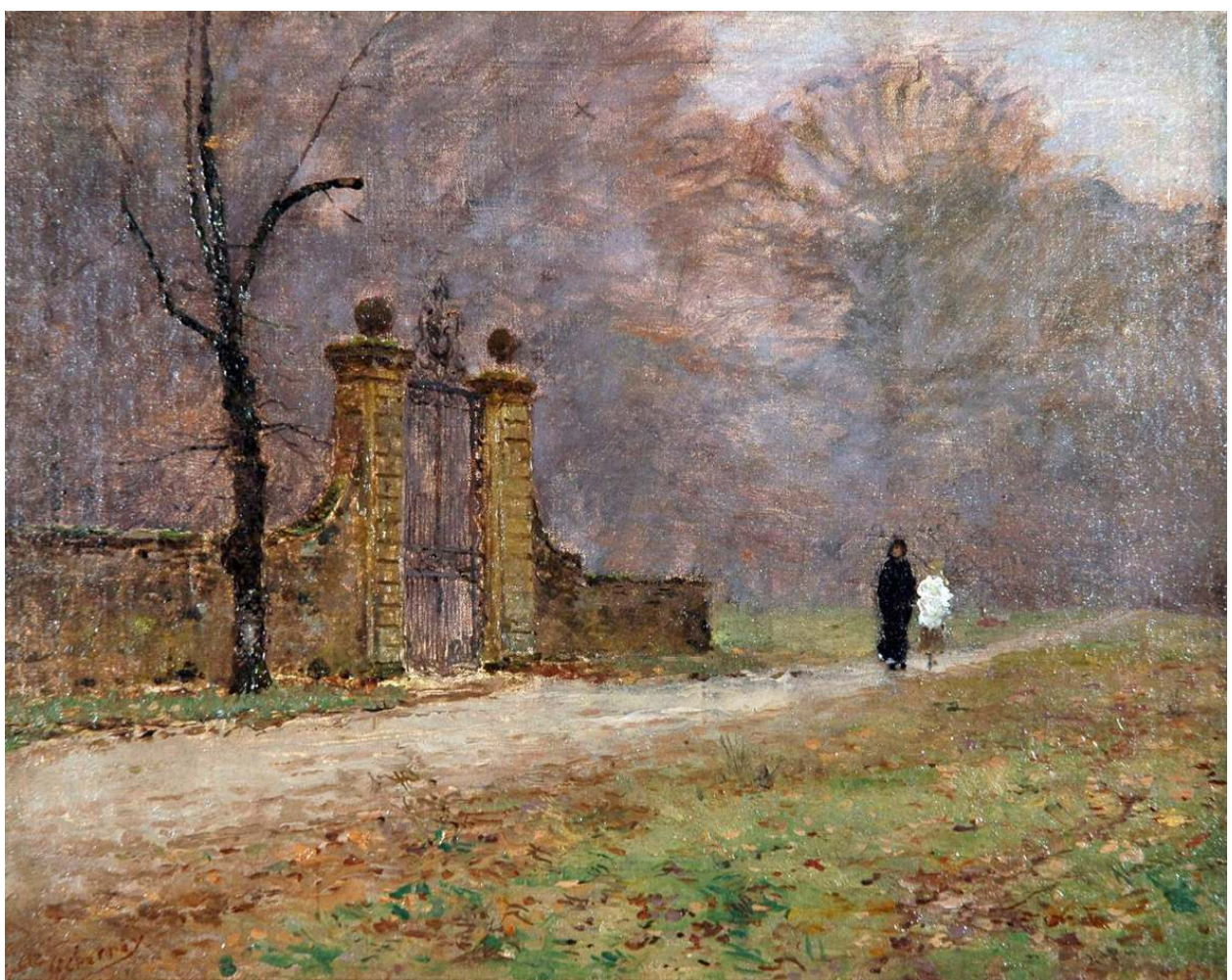

Armand Charnay, Brouillard d'octobre.

Coll. Musée de Charlieu MC-CC 97.01.03. () Musée de Charlieu.

Deux éléments viennent étayer cette hypothèse d'une identification - consciente ou non de Charnay au milieu aristocratique à travers des objets symboliques. Le premier peut être observé dans un tableau représentant la maison natale de l'artiste: belle maison bourgeoise... à laquelle, sur la toile, il rajoute une tour qui n'a jamais existé (fig. 24). 


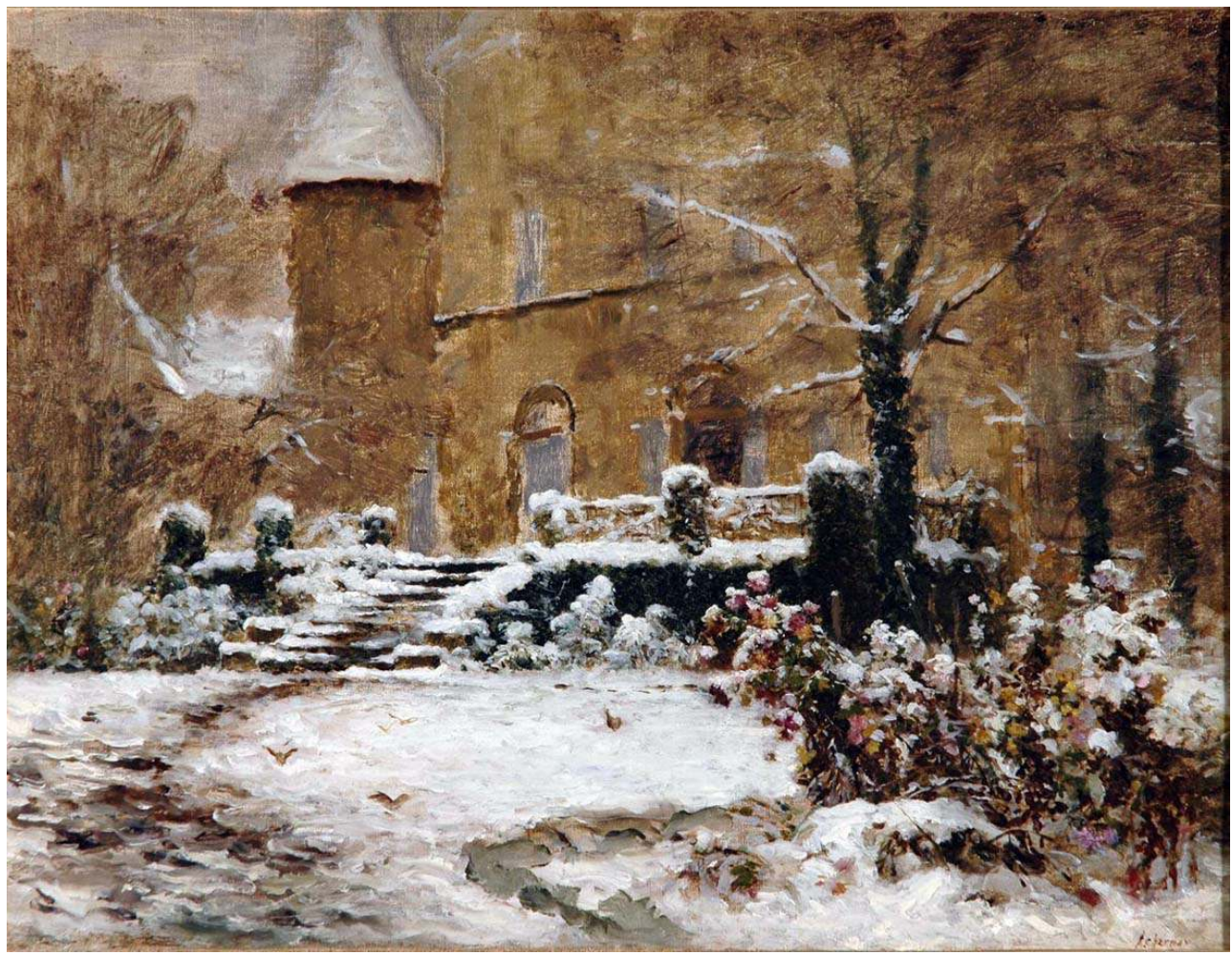

Armand Charnay, Chrysanthèmes sous la neige. Le jardin paternel à Charlieu.

Coll. Musée de Charlieu MC-CC 97.01.197. ( ) Musée de Charlieu.

Le deuxième est encore plus éloquent: le peintre, voulant se faire bâtir une maison à Marlotte, prit pour modèle un bâtiment d'Ancien Régime, l'hôtel Pompadour à Fontainebleau, seul exemple de ce type parmi les maisons luxueuses construites pendant la même période à Bourron et à Marlotte (fig. 25). 


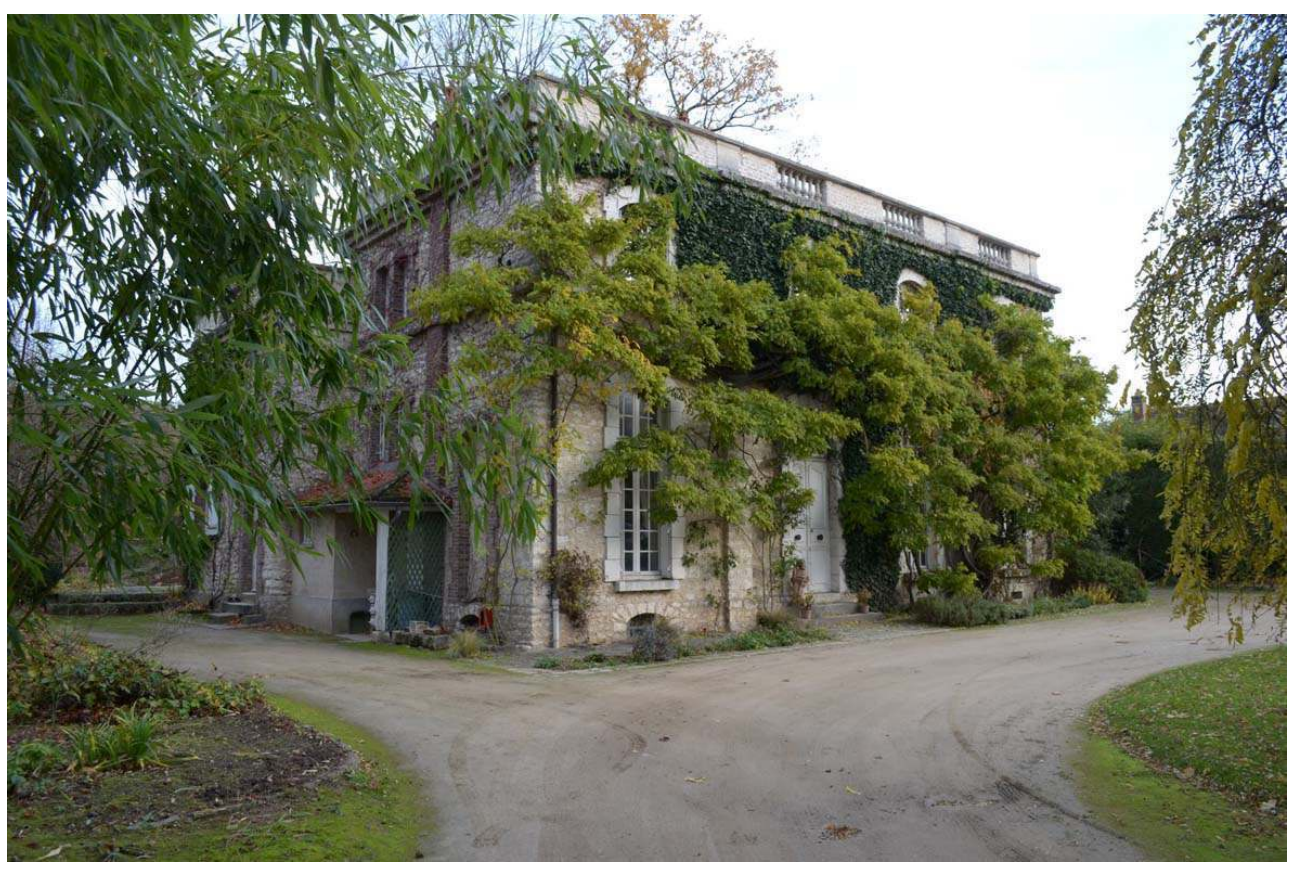

La maison d'Armand Charnay à Bourron-Marlotte.

PHOT. LAgER, THIERRY. @ T. LAgER, 2012.

\section{Conclusion}

La représentation du cheval dans l'œuvre de Charnay ne traduit pas, comme ce fut le cas pour de nombreux artistes de son époque, une attirance particulière pour l'animal en tant que tel ou une pratique assidue d'une discipline équestre à la façon d'un Carle Vernet, d'un Théodore Géricault ou d'une Rosa Bonheur. Les chevaux de chasse à courre, compagnons de l'aristocratie, si souvent représentés par Charnay, prennent une tout autre dimension et délivrent, à n'en pas douter, un message sur la personnalité de l'artiste. Le rapport à l'animal est ici signifiant quant à la psychologie du peintre, comme il l'est par exemple chez Courbet. Dans les deux cas, l'animal - ici, le cheval - est un messager des sentiments, une expression subliminale d'un ressenti et d'une aspiration profonde. À travers la représentation des chevaux de vènerie, Charnay manifeste son désir de pénétrer dans une sphère sociale pour laquelle il éprouve une attirance et à laquelle il tend à s'identifier.

25 Qui sait s'il ne rêve pas aussi à un impossible amour de jeunesse, incarné par la jeune femme si souvent figurée devant le château de Gatellier? 


\section{BIBLIOGRAPHIE}

TABARD, Daniel. Armand Charnay 1844-1915. Charlieu : musée de Charlieu, 2002.

MIGUET, Danièle. « Le rivage vu par Armand Charnay ». Dans OLIVIER, Brigitte et MIGUET, Danièle. Peindre le rivage : Denis, Marquet, Dufy. Gray : Ville de Gray/musée Baron Martin, 2012, p. 26-31.

MIGUET, Danièle. « La représentation cynégétique dans l'œuvre d'Armand Charnay ». Bulletin d'Information et de liaison de l'association des Amis de Bourron-Marlotte, 2012, n 54, p. 23-26.

MIGUET, Danièle. « Yport vu par Armand Charnay ». Dans DELARUE, Bruno (dir.). Armand Charnay, 1844-1915, Yport 1874. Catalogue d'exposition. Yport : Terre en vue, 2010, p. 8-30.

MIGUET, Danièle. « Armand Charnay et la chasse ». Dans PAILLER, Henri, et DEVIN, Séverine (dir.) Tableaux de chasse. Catalogue d'exposition, Usson-en Forez, écomusée des monts du Forez, 28 mai-31 décembre 2011. Saint-Étienne : musée d'Usson-en-Forez, 2011, p. 26-29.

\section{NOTES}

1. - 185 huiles sur toile, 70 huiles sur autres supports, 86 fusains, 154 dessins sur papier ou toile fine, 184 dessins sur calque, 11 aquarelles, 21 lithographies, pastels et eaux-fortes.

2. - Ont été retirées de ce décompte les multiples de l'estampe intitulée Le bac de la ferme.

3. - 1905-1997, né à Roanne.

4. - Giovanni Fattori, 1825-1908, peintre du mouvement des Macchiaioli, auteur de nombreux paysages de la Maremme.

5. - 1813-1894, peintre de l'École de Barbizon.

6. - Film d'Harry Lachmann de 1932.

7. - Membres d'un équipage.

8. - CHARNAY, Armand. "Combat de perdrix rouges et de perdrix grises ». La chasse illustrée, 28 août 1868.

\section{RÉSUMÉS}

Bien qu'il ne soit pas considéré comme peintre animalier, Armand Charnay (1844-1915) a peuplé ses toiles et dessins de très nombreux animaux, toujours représentés avec exactitude et vivacité. Parmi ceux-ci, les chevaux figurent en bonne place et il est intéressant de s'interroger sur les types de chevaux figurés et les activités humaines auxquelles ils sont associés. Quel regard un homme de la bourgeoisie comme ce fils de notaire, artiste, ayant toujours vécu dans un environnement rural, d'abord à Charlieu, dans la Loire, puis à Marlotte, en forêt de Fontainebleau, porte-t-il sur cet animal ? Comment le représente-t-il ? A contrario, quelles sont 
les utilisations équines totalement absentes de son œuvre? Telles sont quelques-unes des interrogations auxquelles tentera de répondre cet article en établissant des comparaisons avec d'autres artistes contemporains et en montrant que les choix en la matière traduisent une vision sociale particulière et révèlent des aspirations dépassant très largement le cadre de la simple représentation d'une espèce animale.

The representations of horses in the work of a late-nineteenth-century artist, Armand Charnay. Although he is not considered as a wildlife artist, Armand Charnay (1844-1915) populated his paintings and drawings with many animals, depicting them with accuracy and vividness. Among these animals, horses are often present, and it is interesting to consider the types of horses he shows and the human activities with which they are associated. The artist came from the middle class, the son of a notary, who always lived in a rural environment, first in Charlieu, in the Loire department, then in Marlotte in the forest of Fontainebleau. How did he see the horse? How did he represent it? What horse-related activities do not feature in his work? These are some of the questions that this paper will look at, making comparisons with other modern artists. It will be suggested that the pictures of horses reflect a particular social vision and reveal aspirations that go beyond the mere representation of an animal species.

INDEX

Mots-clés : cheval, Charnay, Marlotte, Fontainebleau, équitation, chasse à courre, XIXe siècle, peinture, dessin

Keywords : horse, horse-riding, hunting, nineteenth century, painting, drawing

\section{AUTEUR}

\section{DANIÈLE MIGUET}

Conservateur en chef du patrimoine. Musée de Charlieu (Loire) miguet.d@gmail.com 